\title{
Thermal Structure of a Coastal-Urban Boundary Layer
}

\author{
David Melecio-Vázquez ${ }^{1}$ (D) Prathap Ramamurthy ${ }^{1} \cdot$ Mark Arend $^{2} \cdot$ \\ Jorge E. González-Cruz ${ }^{1}$
}

Received: 26 May 2017 / Accepted: 14 May 2018 / Published online: 31 May 2018

(C) The Author(s) 2018

\begin{abstract}
We use various temperature profilers located in and around New York City to observe the structure and evolution of the thermal boundary layer. The primary focus is to highlight the spatial variability of potential-temperature profiles due to heterogeneous surface forcing in an urban environment during different flow conditions. Overall, the observations during the summer period reveal the presence of thermal internal boundary layers due to the interaction between the marine atmospheric boundary layer and the convective urban environment. The summer daytime potential-temperature profiles within the city indicate a superadiabatic layer is present near the surface beneath a mildly stable layer. Large spatial variability in the near-surface $(0-300 \mathrm{~m})$ potential temperature is detected, with the thermal profile in the lower atmosphere uniquely determined by the underlying surface forcing and the distance from the coast. The summer and winter average night-time potential-temperature profiles show that the atmosphere is still convective near the surface. The seasonal averages of mixing ratio show large variability in the vertical direction.
\end{abstract}

Keywords Coastal boundary layer - Microwave radiometer - Moisture boundary layer . Thermal boundary layer · Urban boundary layer

\section{Introduction}

Key knowledge gaps exist in our understanding of boundary-layer processes over coastal cities where the population is projected to increase in the coming years (United Nations 2015). The climatology of coastal cities is simultaneously influenced by the additional convection resulting from anthropogenic activities and sea-breeze incursion, leading to an uncertain

$凶$ David Melecio-Vázquez

dmeleci00@citymail.cuny.edu

1 Department of Mechanical Engineering and NOAA-CREST Center, City College of New York, New York, NY 10031, USA

2 Department of Electrical Engineering and NOAA CREST Center, City College of NewYork, New York, NY 10031, USA 
thermal environment because of the high vulnerability to extreme temperatures. However, the lack of adequate observations at appropriate spatial and temporal scales inhibits our ability to produce accurate boundary-layer forecasts in urban environments, which is important for emergency-responses purposes (National Research Council 2012).

Over the last 30 years, many observational and numerical experiments have been conducted with which to study the urban boundary layer. Problems related to air pollution (Molina and Molina 2004) and the threat of terrorism (Batchvarova and Gryning 2006) have led to many dispersion studies in Europe and the USA. The Joint Urban 2003 field campaign in Oklahoma City and the BUBBLE (Basel Urban Boundary-Layer Experiment) campaign in Switzerland are examples of large-scale, urban-dispersion campaigns capturing the urban-rural differences in boundary-layer structure (Rotach et al. 2005). The data from these studies have been helpful in improving the representation of urban-scale processes in numerical weather prediction (Salamanca and Martilli 2010) and air-pollution models (Batchvarova and Gryning 2006; Franzese and Huq 2011). However, their applicability in coastal-urban environments is questionable. While very few experiments have been conducted to investigate coastal-urban interactions, Mestayer et al. (2005) have observed the variation of the boundary-layer height during sea-breeze events in Marseille during the ESCOMPTE campaign, noting that the sea breeze tends to weaken boundary-layer development (Lemonsu et al. 2006) despite the increasing insolation as the day progresses into the afternoon; a similar behaviour was also found by De Tomasi et al. (2011) in Lecce, Italy. We do not refer to these experiments to provide an exhaustive list of urban boundary-layer studies, but to emphasize the fact that very few observations exist on the thermal characteristics of the urban boundary layer (Barlow 2014). Further, most experiments focus on the urban surface layer, whereas we seek to investigate the structure of the urban boundary layer here by extending observations to the entrainment zone (typically $2-3 \mathrm{~km}$ above ground level).

While relatively few surface parameters are required to estimate the vertical structure of the boundary layer over homogeneous terrain, the high degree of surface heterogeneity and the influence of the sea breeze in coastal-urban zones require knowledge of the flow history (De Tomasi et al. 2011). In New York City, observations of urban heat islands and cool islands (Gaffin et al. 2008; Meir et al. 2013) cannot be solely explained using surface characteristics. Based on helicopter transects in the 1960s, Bornstein (1968) revealed that neighbourhoods closer to the coast experience rural-like surface inversions. Here, we investigate the variability of the urban boundary layer in New York City using vertical profiles from three local airports, and profiles derived from a microwave radiometer within the urban centre to investigate the seasonal variabilities in the thermal and moisture boundary-layer structure. Microwave radiometers have the advantage of being robust instruments $\mathrm{Xu}$ et al. 2015), with a recent, extensive study judging them to be very good at estimating temperature profiles, particularly in the lower boundary layer (Lundquist et al. 2017). While microwaveradiometer observations have been used to determine the mixed-layer height (Cimini et al. 2013), the vertical extent of the urban heat island (Khaikine et al. 2006), and for estimating stability conditions for wind-energy applications (Friedrich et al. 2012), our main objectives here are to analyze the spatial variability in the thermal structure of the boundary layer over the highly dense area of New York City, and to quantify the diurnal and seasonal variabilities of the urban thermal and moisture profiles. 


\section{Measurements and Data Analysis}

A Radiometrics profiling radiometer, model MP-3000A (Radiometrics, Boulder, Colorado, USA), is located on the roof of the engineering building at the City College of New York (CCNY) $\left(40.821519^{\circ} \mathrm{N}, 73.948184^{\circ} \mathrm{W} ; 65 \mathrm{~m}\right.$ above sea level), and is part of the New York City Meteorological Network (NYCMetNet) (National Research Council 2012, 54). This microwave radiometer is a passive instrument that records vertical profiles of temperature, relative humidity, water vapour and liquid water density. Profiles are produced from brightness temperatures measured in several bands centred at different frequencies, with temperature from the $60-\mathrm{GHz}-$ centred feature, water vapour from the $22-\mathrm{GHz}$ feature, and liquid-water profiles from a combination of scans in the $22-$ to $30-\mathrm{GHz}$ and $51-$ to $59-\mathrm{GHz}$ bands. The brightness temperatures are then converted to vertical profiles of the above-mentioned variables using a neural-network algorithm based on radiosonde-derived observations. The neural-network output contains 58 levels with varying vertical spacing: 0 to $500 \mathrm{~m}$ in $50-\mathrm{m}$ steps, 600 to $2000 \mathrm{~m}$ in 100-m steps, and 2,250 $\mathrm{m}$ to $10,000 \mathrm{~m}$ in 250-m steps. At every level, the potential temperature is calculated using

$$
\theta=T\left(p_{0} / p\right)^{0.286}
$$

where $T$ is the temperature measured by the microwave radiometer in $\mathrm{K}, p_{0}$ is the reference pressure of $1013 \mathrm{hPa}$, and $p$ is the pressure derived from the heights of a standard atmosphere (Wallace and Hobbs 2006). The pressure information is then used to estimate the mixing ratio at each level using (Stull 1988)

$$
\begin{gathered}
e_{\text {sat }}=0.611 \exp \left(\frac{17.27(T-273.16)}{T-35.86}\right), \\
r_{\text {sat }}=0.622 \frac{e_{\text {sat }}}{P-e_{\text {sat }}}
\end{gathered}
$$

and

$$
r_{v}=\frac{R H}{100} r_{s a t},
$$

where $e_{\text {sat }}$ is the saturation water-vapour pressure in $\mathrm{kPa}, r_{\text {sat }}$ is the saturation water-vapour mixing ratio, $r_{v}$ is the water-vapour mixing ratio that is used as the absolute measure of moisture for the atmosphere, and is calculated from the relative humidity, $R H$, as measured by the microwave radiometer.

The microwave-radiometer profiles are compared with the American Meteorological Data Reports (AMDAR), which have been aggregated from several airlines to form records of varying temporal and spatial resolution. The root-mean-square error was reported to be around $0.72 \mathrm{~K}$ for the 900-800 hPa levels in the boundary layer (Benjamin et al. 1999). The boundary-layer profiles are from the John F. Kennedy International Airport (JFK; $40.6413^{\circ} \mathrm{N}, 73.7781^{\circ} \mathrm{W}$ ) located on the Atlantic Coast, LaGuardia Airport (LGA; $40.7769^{\circ} \mathrm{N}$, $73.8740^{\circ} \mathrm{W}$ ) located $23 \mathrm{~km}$ west of the Atlantic Coast, and Newark Liberty International Airport (EWR; $\left.40.6895^{\circ} \mathrm{N}, 74.1745^{\circ} \mathrm{W}\right)$. It is important to point out that the AMDAR altitude values are derived from a pressure altitude based on a standard atmosphere. To calculate the true height of the measurement, the method outlined in Rahn and Mitchell (2016) is employed using publicly available observations from the Automatic Surface Observing Systems network for the surface conditions at each site.

Figure 1 shows a map of the region being analyzed. According to Stewart and Oke (2012), the airport locations (LGA, JFK, and EWR sites) can be categorized as a Local Climate Zone 8, 
and the CCNY site as a Local Climate Zone 1, which is mostly high-rise residential buildings with an average height of 25-65 m. Additional information on the land-use categories for New York City can be found in Gutiérrez et al. (2015a), where high-resolution, land-cover information was used for mapping the urban morphology (e.g., the building height and landuse category according to Fry et al. 2011). The land-use characteristics around each airport are as follows: around the JFK site are low-rise residential units, around the LGA site are high-rise residential and commercial units, while the EWR site is surrounded by a commercial district, with average building heights adjacent to each airport of 8.5-10, 15-25, and 8-10 m, respectively.

The spatial variability of the urban boundary layer is investigated for selected dates during the month of July 2016 using observations from the microwave radiometer and AMDAR records. As the timestamps for the microwave radiometer and AMDAR records are not concurrent, these data were matched within \pm 14 min and $59 \mathrm{~s}$ (to avoid duplicate records) between 0000 LST (local standard time) on 1 July 2016 to 2330 LST on 31 July 2016, in 30-min intervals. This process resulted in approximately 300 dates on which the microwave radiometer and AMDAR records occurred within a 30-min window. The dates were further narrowed to select cloudless days over all four locations, which resulted in the selection of different dates for each time-of-day, since no data were available spanning an entire day from all four sites. The timestamps in Fig. 1 do not correspond to the exact time of the observation, but represent the closest matched time. The dates chosen are during the extreme-heat episodes investigated in more detail in Ramamurthy et al. (2017a). Additionally, the potential-temperature $(\theta)$ gradient at each location was calculated by performing a linear regression on the $\theta$ data available in each layer. The slope of the linear regression equation was then recorded as the potential-temperature gradient, $d \theta / d z$. Wind-speed profiles are available only for the AMDAR locations, since no wind-speed data are available at the CCNY location.

For the averaged profile analysis, only data from the microwave radiometer were used. Clear-sky observations from June to August 2015 were used to compute summer averages, with clear-sky observations from December 2014 to February 2015 used to calculate winter averages. The data were separated into bins for different time periods, and then again for every microwave-radiometer measurement height; the daytime and night-time hours for each season correspond to 1000-1600 LST (1400-2000 UTC) and 2200-0400 LST (0200-0800 UTC), respectively.

\section{Results and Discussion}

\subsection{Spatial Variability}

Figure 1 shows the spatial variability of the boundary layer over New York City by comparing the temperature (microwave radiometer and AMDAR) and wind-speed (AMDAR only) profiles, including the ground track of the flights used. As mentioned earlier, the altitudes were corrected to enable the direct comparison: AMDAR records were corrected with data obtained from surface stations and the hypsometric equation, while microwave-radiometer data were adjusted to account for the height of the instrument above sea level. Figure 1a compares the microwave-radiometer observations with AMDAR profiles, while Fig. 1b, c shows the wind-speed and wind-direction profiles, respectively, from the AMDAR locations only. Each column of Fig. 1 shows a typical transition of the boundary layer over the coastal-urban environment in New York City, and highlights the spatial variability within such a densely 

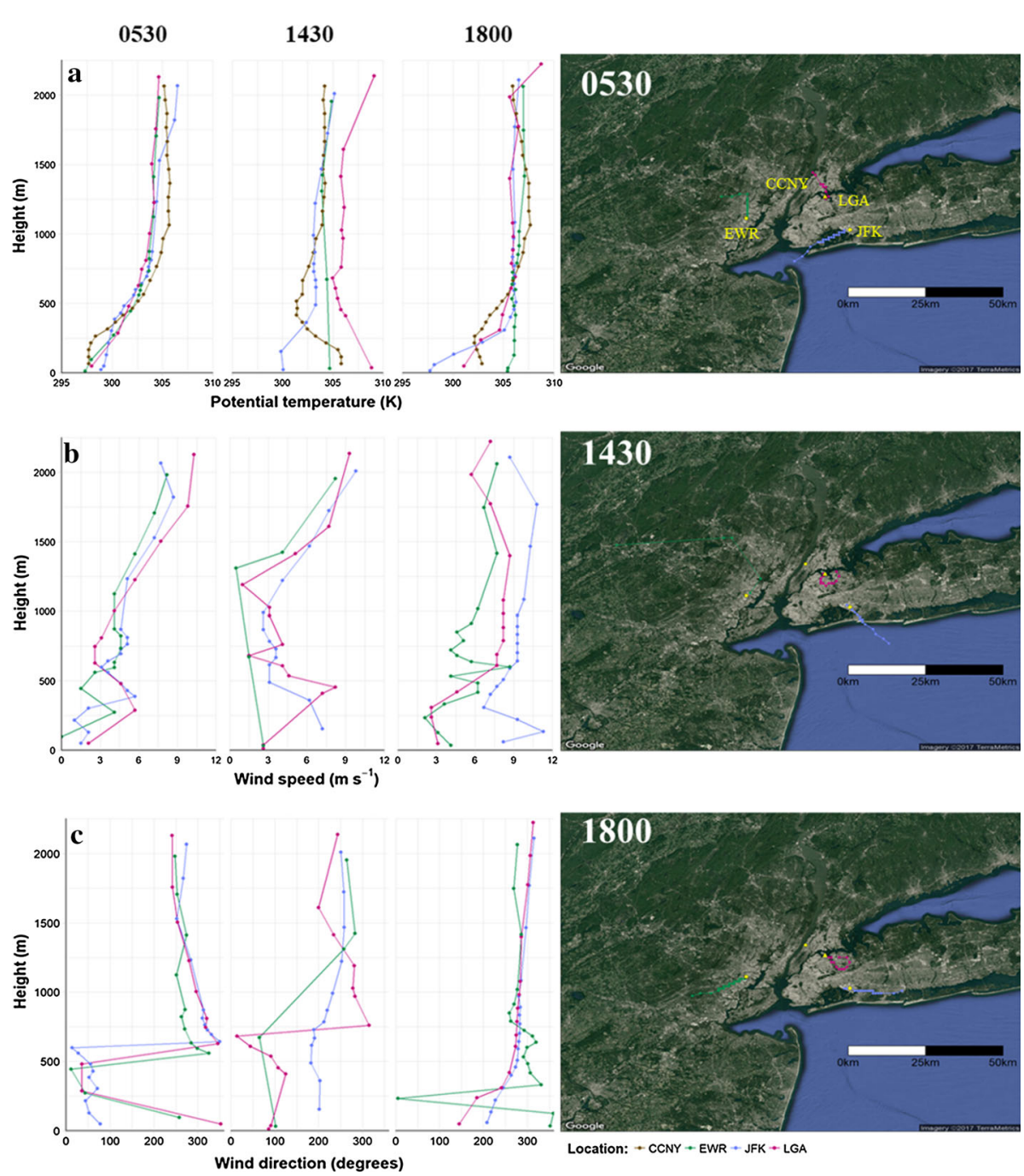

Fig. 1 Profiles of a potential temperature, $\mathbf{b}$ wind speed and $\mathbf{c}$ wind direction from different locations across New York City. Each column corresponds to a different hour of the day. The 0530 LST timestamp corresponds to near-sunrise profiles (sunrise is at 0538 LST) on 16 July 2016. The 1430 LST data represent the early afternoon on 16 July 2016. The 1800 LST data represent the late afternoon on 24 July 2016, with sunset at 2019 LST. The maps show the ground track of the flights used. The following wind-speed profiles in $\mathbf{b}$ and $\mathbf{c}$ have a missing value at the first level: the JFK and EWR sites at 0530, the JFK site at 1430, and the JFK and EWR sites at 1800

populated coastal-urban environment. Each location has a different footprint that affects the development of the boundary-layer profiles. The profiles at the JFK site (coastal site, Fig. 1a) are usually influenced by onshore flow advecting cooler (with the exception of Fig. 1a -0530 LST showing the flow from the east), saturated airmasses over the city during the warm season (Gedzelman et al. 2003; Bailey and Freedman 2008). The EWR site is located inland, with potential-temperature profiles resembling those over homogeneous terrain, especially during the convective period around 1430 LST as shown in Fig. 1a. Potential-temperature 
gradients for these profiles were calculated for the levels $0-300 \mathrm{~m}$ to contrast the stability at each location.

In the early morning hours before sunrise, the atmosphere is stable over all airport locations, and weakly stable over the CCNY site. The wind direction during this period is from the north (from land), and wind speeds $<5 \mathrm{~m} \mathrm{~s}^{-1}$ are visible in the near-surface region. The $\theta$ gradient values below the 300 -m level show very stable to weakly-stable layers for each location. The EWR and LGA locations are upstream of the change in surface roughness and, thus, show a more stable layer with values of 11 . and $11.4 \mathrm{~K} \mathrm{~km}^{-1}$, respectively for the gradient. Downstream, less stable layers can be seen at the CCNY and JFK locations, with gradients of 6.6 and $3.5 \mathrm{~K} \mathrm{~km}^{-1}$, respectively, since roughness elements may be generating turbulence, resulting in a near-adiabatic layer (as noted in Godowitch et al. 1985, 1987, and Day et al. 2010) extending from the surface up to $200 \mathrm{~m}$ at the CCNY site, and up to $375 \mathrm{~m}$ at the JFK site. Anthropogenic heat sources may also play a role in maintaining the weakly stable layers found at these locations.

The transition to the daytime convective period (see Fig. 1-1430 LST column) reveals the spatial variation within the city. The thermal boundary layer (Fig. 1a) over the EWR site is well-mixed and with a typical structure of a convective boundary layer over land, while the wind speeds are low and from the east (from water). The $\theta$ profile at the JFK site is consistent with a daytime marine boundary layer, since the flow is from the south (from water). At the JFK location, the air temperature close to the surface is lower, with a $\theta$ gradient of $10.7 \mathrm{~K} \mathrm{~km}^{-1}$; at the LGA site, the superadiabatic layer with a $\theta$ gradient of $-9.4 \mathrm{~K} \mathrm{~km}^{-1}$ reaches up to $650-700 \mathrm{~m}$.

The boundary layer over the CCNY site has an interesting and unique structure. The near-surface $\theta$ gradient is $-15.4 \mathrm{~K} \mathrm{~km}^{-1}$, which may have been additionally affected by the anthropogenic heat released from the dense urban environment. The superadiabatic region ends at around $250 \mathrm{~m}$ where an elevated mixed layer can be seen, which is consistent with the profile at the JFK site. Although a more detailed analysis is required, the marine boundary layer may have generated a capping stable layer starting at around $375 \mathrm{~m}$. Above $1000 \mathrm{~m}$, the CCNY profile is comparable to the LGA profile, and both exhibit a well-mixed region. The stable region between $375 \mathrm{~m}$ and $1000 \mathrm{~m}$ may inhibit efficient mixing within the boundary layer, which has implications for air-pollution applications, since most convective schemes over the city ignore the formation and development of thermal internal boundary layers independent of the near-surface fluxes.

While the coastal JFK site is influenced by the sea breeze during the afternoon periods, as seen by the southerly winds in Fig. 1b, the sea breeze is unable to penetrate inland to the LGA and CCNY sites, which are influenced by the northerly land breezes. The low wind speeds at the EWR site and the nearly-adiabatic temperature profile show that the penetration of the sea breeze is insufficient to perturb the thermal profile from mean adiabatic conditions.

Moving into the evening hours, (see Fig. 1, 1800 LST column), surface cooling resulted in a stable boundary layer at all locations, except at the CCNY site. At the JFK site, wind speeds from the south $\approx 8 \mathrm{~m} \mathrm{~s}^{-1}$ (the highest near-surface wind speeds across all locations), and the $\theta$ gradient is $26.9 \mathrm{~K} \mathrm{~km}^{-1}$. At the CCNY location, the stable layer from 250 to $500 \mathrm{~m}$ undergoes a transition from $3.2 \mathrm{~K} \mathrm{~km}^{-1}$ at $1430 \mathrm{LST}$ to a larger $10.6 \mathrm{~K} \mathrm{~km}^{-1}$ at 1800 LST. However, in the lower $250 \mathrm{~m}$, a superadiabatic layer is visible with a $\theta$ gradient of $-1.0 \mathrm{~K} \mathrm{~km}^{-1}$. All profiles begin to collapse into a similar thermal regime starting at around $750 \mathrm{~m}$. The strong stable conditions present across most of the region on the edges of the urban environment suggest the persistence of temperatures resulting from anthropogenic heating within the urban environment throughout most of the night. 


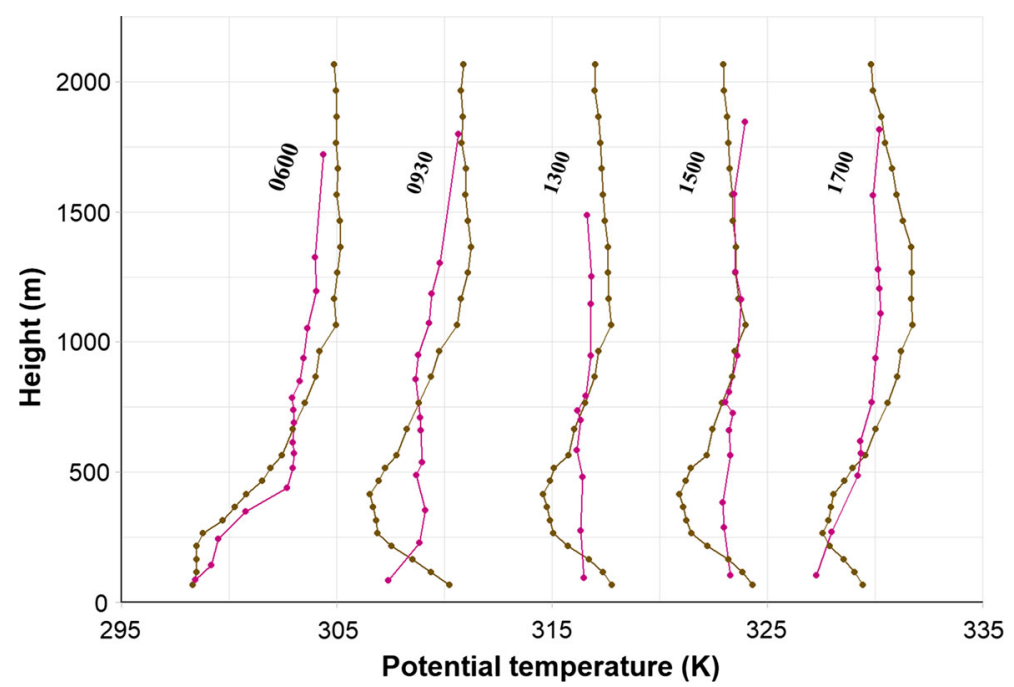

Fig. 2 Transition of potential temperature at different hours on 6 July 2016. Sunrise was at 0530 LST, and sunset was at 2030 LST. Location: brown filled circle: CCNY, pink filled circle: LGA

In summary, different mechanisms influence the development of the boundary layer in New York City. Internal boundary layers form downstream of discontinuities in surface characteristics (Garratt 1990), such as the geometry, temperature, humidity, and/or surface fluxes. In the profiles from the CCNY site, there is evidence of internal boundary layers forming due to the surface roughness, as can be seen by the persistent profiles in the boundary layer, where a superadiabatic layer forms near the surface, which slowly undergoes transition into a sub-adiabatic region below the elevated mixed layer.

During the convective conditions from midday into the evening, the EWR profile shows increased temperatures compared with the coastal profiles at the JFK site, and is more comparable to the profiles that occur inland. These differences are most apparent during the afternoon hours when the sea breeze plays a dominant role, as seen by the flow from the south over the JFK site.

Figure 2 shows the transition of the thermal boundary layer at the CCNY and LGA sites, with similar stability features in the early morning just after sunrise detected at both locations. As the day progresses, a superadiabatic layer persists throughout the day over the CCNY location, whereas the LGA profiles illustrate a transition from stable to convective, and back to stable conditions. The profiles at both locations indicate stable conditions at a height $\approx 750 \mathrm{~m}$ throughout the day. The superadiabatic region over the city may be the result of a combination of anthropogenic heating from below and the capping produced by the sea breeze above preventing the exchange of the higher temperature air with layers aloft.

\subsection{Average Boundary-Layer Profiles}

The average nocturnal and diurnal $\theta$ profiles are presented here for both the winter and summer seasons based only on data from the microwave radiometer collected at the CCNY location, and divided into summer-day and summer-night, and winter-day and winter-night, categories averaged over 11,968,11,009,15,522, and 13,566 profiles, respectively. Figure 3 shows the average vertical profile of daytime/night-time pairs of the potential temperature 


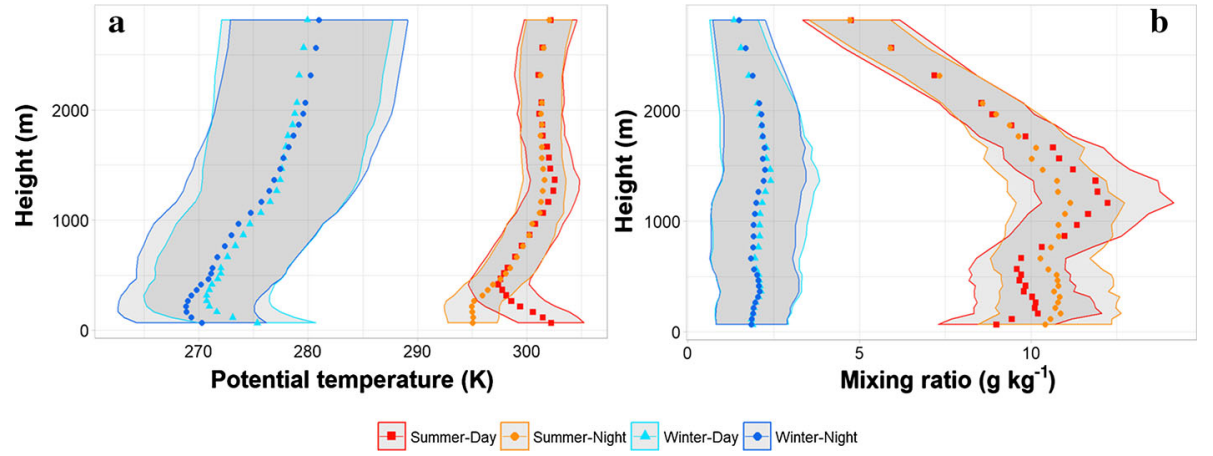

Fig. 3 Summer and winter profiles, a potential temperature, and b mixing ratio. Diurnal- and nocturnalaveraged profiles for each respective season are shown for clear-sky conditions only. Grey areas indicate the extent of one standard deviation

and the mixing ratio for the summer and winter periods. The grey areas represent one standard deviation from the mean value of each averaged profile. The mean difference between the summer and winter daytime profiles at each level amounts to $25.4 \mathrm{~K}$ for the potential temperature and $7.8 \mathrm{~g} \mathrm{~kg}^{-1}$ for the mixing ratio. The standard deviation of the daytime summer and winter potential temperature averaged for the entire column is 2.7 and $6.0 \mathrm{~K}$, respectively, with corresponding standard deviations of 1.6 and $1.2 \mathrm{~g} \mathrm{~kg}^{-1}$ for the summer and winter daytime mixing ratios, respectively. Strong organized thermals during the summer daytime convective period may lead to a reduced overall randomness in the profile, which can be seen by the lower range of the values for the summer daytime average relative to the winter daytime average in Fig. 3 a.

The winter $\theta$ profiles in Fig. 3a show a superadiabatic layer starting at the instrument level and extending upwards to about 125 and $250 \mathrm{~m}$ for the daytime and night-time profiles, respectively. The $\theta$ gradients for the layer from 0 to $300 \mathrm{~m}$ are -18.7 and $-22.8 \mathrm{~K} \mathrm{~km}^{-1}$ for the summer and winter daytime profiles, respectively, with night-time gradients of 0.3 and $-6.1 \mathrm{~K} \mathrm{~km}^{-1}$, respectively. In the layer $150-200 \mathrm{~m}$, an elevated stable layer can be identified. While a stable layer at the surface is usually expected over urban areas, this layer is elevated due to anthropogenic heating and/or mechanical turbulence generated by the urban roughness elements. The daytime and night-time boundary-layer heights are around 350 and $900 \mathrm{~m}$ based on the parcel method (Seidel et al. 2010). Other cities in the USA have been reported to have a superadiabatic layer close to the surface at night in urban areas; in St. Louis, a mean inversion base height for the nocturnal boundary layer is estimated as $150 \mathrm{~m}$ above a nearly adiabatic region (Godowitch et al. 1985); and in Houston, Texas, a mean inversion base height of $203 \mathrm{~m}$ has been observed (Day et al. 2010). The presence of the superadiabatic layer may be explained by the larger heat-storage capacity of the urban environment, and through radiative cooling of the surface at night. Hence, elevated stable layers over urban areas are often seen during convective periods (Bornstein 1968; Godowitch et al. 1985).

The summer profiles show convective and stable boundary layers for the day and nighttime, respectively. The average daytime mixed-layer depth is estimated to be $2.75 \mathrm{~km}$, with an average superadiabatic layer extending from the instrument level to a height of $350 \mathrm{~m}$. The elevated stable layer results in $\Delta \theta \approx 5 \mathrm{~K}$ based on the bottom of the stable layer near $400 \mathrm{~m}$ to the top of the stable layer near $1250 \mathrm{~m}$. Just above this layer is a level of statically neutral air of 600-m thickness. The night-time profile shows a stable layer from the instrument level until about $400 \mathrm{~m}$ where the $\theta$ profile shows higher temperatures than the daytime profile. 
To the authors' knowledge, few observational studies have focused on the vertical structure of humidity, except as a proxy for inferring the boundary-layer height (Haman et al. 2012), or the structure has been estimated using high-resolution model data (Lemonsu et al. 2006; Huang et al. 2016). The observed daytime mixing-ratio profile shown in Fig. $3 \mathrm{~b}$ has two maxima. Here, the land- and/or sea-breeze interactions may play a role: during a sea breeze, the advected moisture is located near the surface, but aloft during a land breeze. It is interesting to note that the stable layer in the daytime profiles coincides with an increase in the mixing ratio at the same level. The presence of moisture may influence the thermal environment by reducing the convective efficiency of plumes rising from the surface.

The large variability during the winter periods can be attributed to the decoupling of the surface layer from the layers aloft (Markowski and Richardson 2010). The stable layer above may either be affected by a low-level jet, with increased shear above and below a wind-speed maximum, or to the inability of the stable boundary layer to reach a steady-state due to wake turbulence generated from the urban roughness (Stull 1988).

\section{Conclusions}

Coastal boundary layers form as a direct response to the surface forcing and flow history, with the effects of the former well established in the literature relative to the effects of the latter on boundary-layer development over urban areas. Here we investigate the structure of boundary-layer profiles of temperature and humidity over New York City. While local forcing overwhelmingly dominates the structure of the boundary layer during the daytime, a similar profile structure can be seen at all locations during the night-time, especially above $400 \mathrm{~m}$.

One of the unique features evident in our results is the interaction between the highly convective urban surface layer and the marine boundary layer, leading to the development of an internal boundary layer. Unlike a traditional boundary layer observed over non-coastal and non-urban surfaces, we do not see a uniformly mixed layer, but rather a stable layer during clear, daytime conditions.

While we present the mean thermal characteristics of the coastal-urban environment here, additional work is necessary to study the turbulent transport of heat, momentum and moisture within the coastal-urban boundary layer. Current numerical weather prediction models used in the study of the urban boundary layer (e.g., Leroyer et al. 2014; Gutiérrez et al. 2015b; Ortiz et al. 2016; Ramamurthy et al. 2017b) lack a realistic representation of urban-coastal interactions, since boundary-layer parametrizations are unable to reproduce the thermal internal boundary layers observed. More effort and sustained observations are necessary to improve the predictability of the thermal conditions in the coastal-urban environment.

Acknowledgements This work was supported by the National Oceanic and Atmospheric Administration, Office of Education Partnership Program award NA16SEC4810008, Department of Defense Army Research Office, W911NF-15-1-0443 and by the U.S. Department of Education-Earth Science and Environmental Sustainability (ESES) Graduate Initiative, award P031M105066. Access to AMDAR data and Automatic Surface Observing Systems data was provided via the NOAA (National Oceanic and Atmospheric Administration) Meteorological Assimilation Data Ingest System and has been authorized according to agreements made between the CCNY NOAA Center for Earth System Sciences \& Remote Sensing Technologies, NOAA and NOAA's partners in accordance with the Memorandum of Understandings that NOAA has made with its partners. The authors wish to thank the Brookhaven National Laboratory for their support in preparing this manuscript. The Brookhaven National Laboratory is supported by the U.S. Department of Energy Office of Science. The opinions and conclusions herein are solely those of the authors and do not represent the 
views of the Department of Education, Department of Commerce, the National Oceanic and Atmospheric Administration, the Department of Energy, and the Brookhaven National Laboratory.

Open Access This article is distributed under the terms of the Creative Commons Attribution 4.0 International License (http://creativecommons.org/licenses/by/4.0/), which permits unrestricted use, distribution, and reproduction in any medium, provided you give appropriate credit to the original author(s) and the source, provide a link to the Creative Commons license, and indicate if changes were made.

\section{References}

Bailey BH, Freedman JM (2008) A regional assessment of the US offshore wind energy resource through the use of mesoscale modeling. Mar Technol Soc J 42:8-18. https://doi.org/10.4031/002533208786829124

Barlow JF (2014) Progress in observing and modelling the urban boundary layer. Urban Clim 10:216-240. h ttps://doi.org/10.1016/j.uclim.2014.03.011

Batchvarova E, Gryning S-E (2006) Progress in urban dispersion studies. Theor Appl Climatol 84:57-67. htt ps://doi.org/10.1007/s00704-005-0144-1

Benjamin SG, Schwartz BE, Cole RE (1999) Accuracy of ACARS wind and temperature observations determined by collocation. Weather Forecast 14:1032-1038. https://doi.org/10.1175/1520-0434(1999)014\% 3C1032:AOAWAT\%3E2.0.CO;2

Bornstein RD (1968) Observations of the urban heat island effect in New York City. J Appl Meteorol 7:575-582. https://doi.org/10.1175/1520-0450(1968)007\%3C0575:ootuhi\%3E2.0.co;2

Cimini D, De Angelis F, Dupont J-C, Pal S, Haeffelin M (2013) Mixing layer height retrievals by multichannel microwave radiometer observations. Atmos Meas Tech 6:2941-2951. https://doi.org/10.5194/amt-6-29 41-2013

Day BM, Rappenglück B, Clements CB, Tucker SC, Brewer WA (2010) Nocturnal boundary layer characteristics and land breeze development in Houston, Texas during TexAQS II. Atmos Environ 44:4014-4023. https://doi.org/10.1016/j.atmosenv.2009.01.031

De Tomasi F, Miglietta MM, Perrone MR (2011) The growth of the planetary boundary layer at a coastal site: a case study. Boundary-Layer Meteorol 139:521-541. https://doi.org/10.1007/s10546-011-9592-6

Franzese P, Huq P (2011) Urban dispersion modelling and experiments in the daytime and nighttime atmosphere. Boundary-Layer Meteorol 139:395-409. https://doi.org/10.1007/s10546-011-9593-5

Friedrich K, Lundquist JK, Aitken M, Kalina EA, Marshall RF (2012) Stability and turbulence in the atmospheric boundary layer: a comparison of remote sensing and tower observations. Geophys Res Lett http s://doi.org/10.1029/2011g1050413

Fry JA, Xian G, Jin S, Dewitz JA, Homer CG, Yang L, Barnes CA, Herold ND, Wickham JD (2011) Completion of the 2006 national land cover database for the conterminous United States. Photogr Eng Remote Sens 77:858-864

Gaffin SR, Rosenzweig C, Khanbilvardi R, Parshall L, Mahani S, Glickman H, Goldberg R, Blake R, Slosberg RB, Hillel D (2008) Variations in New York city's urban heat island strength over time and space. Theor Appl Climatol 94:1-11. https://doi.org/10.1007/s00704-007-0368-3

Garratt JR (1990) The internal boundary layer: a review. Boundary-Layer Meteorol 50:171-203. https://doi.o $\mathrm{rg} / 10.1007 / \mathrm{BF} 00120524$

Gedzelman SD, Austin S, Cermak R, Stefano N, Partridge S, Quesenberry S, Robinson DA (2003) Mesoscale aspects of the urban heat island around New York City. Theor Appl Climatol 75:29-42. https://doi.org/ 10.1007/s00704-002-0724-2

Godowitch JM, Ching JKS, Clarke JF (1985) Evolution of the nocturnal inversion layer at an urban and nonurban location. J Clim Appl Meteorol 24:791-804. https://doi.org/10.1175/1520-0450(1985)024\%3 C0791:eotnil\%3E2.0.co;2

Godowitch JM, Ching JKS, Clarke JF (1987) Spatial variation of the evolution and structure of the urban boundary layer. Boundary-Layer Meteorol 38:249-272. https://doi.org/10.1007/BF00122447

Gutiérrez E, Martilli A, Santiago JL, González JE (2015a) A mechanical drag coefficient formulation and urban canopy parameter assimilation technique for complex urban environments. Boundary-Layer Meteorol 157:333-341. https://doi.org/10.1007/s10546-015-0051-7

Gutiérrez E, González JE, Martilli A, Bornstein R, Arend M (2015b) Simulations of a heat-wave event in New York City using a multilayer urban parameterization. J Appl Meteorol Climatol 54:283-301. https://doi .org/10.1175/JAMC-D-14-0028.1 
Haman CL, Lefer B, Morris GA (2012) Seasonal Variability in the diurnal evolution of the boundary layer in a near-coastal urban environment. J Atmos Ocean Technol 29:697-710. https://doi.org/10.1175/JTECH -D-11-00114.1

Huang Q-Q, Cai X-H, Song Y, Kang L (2016) A numerical study of sea breeze and spatiotemporal variation in the coastal atmospheric boundary layer at Hainan Island, China. Boundary-Layer Meteorol 161:543-560. https://doi.org/10.1007/s10546-016-0177-2

Khaikine MN, Kuznetsova IN, Kadygrov EN, Miller EA (2006) Investigation of temporal-spatial parameters of an urban heat island on the basis of passive microwave remote sensing. Theor Appl Climatol 84:161-169. https://doi.org/10.1007/s00704-005-0154-Z

Lemonsu A, Pigeon G, Masson V, Moppert C (2006) Sea-town interactions over Marseille: 3D urban boundary layer and thermodynamic fields near the surface. Theor Appl Climatol 84:171-178. https://doi.org/10.1 007/s00704-005-0155-y

Leroyer S, Bélair S, Husain SZ, Mailhot J (2014) Subkilometer numerical weather prediction in an urban coastal area: a case study over the Vancouver metropolitan area. J Appl Meteorol Climatol 53:1433-1453. http s://doi.org/10.1175/JAMC-D-13-0202.1

Lundquist JK, Wilczak JM, Ashton R, Bianco L, Brewer WA, Choukulkar A, Clifton A, Debnath M, Delgado R, Friedrich K, Gunter S (2017) Assessing state-of-the-art capabilities for probing the atmospheric boundary layer: the XPIA Field Campaign. Bull Am Meteorol Soc 98:289-314. https://doi.org/10.1175/BAMS-D $-15-00151.1$

Markowski P, Richardson Y (2010) Mesoscale meteorology in midlatitudes. Hoboken, NJ, Wiley-Blackwell

Meir T, Orton PM, Pullen J, Holt T, Thompson WT, Arend M (2013) Forecasting the New York City urban heat island and sea breeze during extreme heat events. Weather Forecast 28:1460-1477. https://doi.org/ 10.1175/WAF-D-13-00012.1

Mestayer PG, Durand P, Augustin P, Baston S, Bonnefond JM, Bénech B, Campiston B, Coppalle A, Delbarre H, Dousset B, Drobinski P (2005) The urban boundary-layer field campaign in Marseille (UBL/CLUESCOMPTE): set-up and first results. Boundary-Layer Meteorol 114:315-365. https://doi.org/10.1007/ s10546-004-9241-4

Molina MJ, Molina LT (2004) Megacities and atmospheric pollution. J Air Waste Manag Assoc 54:644-680

National Research Council (2012) Urban meteorology: forecasting, monitoring, and meeting users' needs. National Academies Press, Washington, p 190

Ortiz LE, Gonzalez JE, Gutierrez E, et al (2016) Forecasting building energy demands for New York City with a coupled weather-building energy model. 10th International Conference on Energy Sustainability, 26-30 June, 2016, Charlotte, North Carolina, USA p V001T11A004

Rahn DA, Mitchell CJ (2016) Diurnal Climatology of the boundary layer in Southern California using AMDAR temperature and wind profiles. J Appl Meteorol Climatol 55:1123-1137. https://doi.org/10.1175/JAMC -D-15-0234.1

Ramamurthy P, González J, Ortiz L, Arend M, Moshary F (2017a) Impact of heatwave on a megacity: an observational analysis of New York City during July 2016. Environ Res Lett 12:54011. https://doi.org/1 $0.1088 / 1748-9326 /$ aa6e59

Ramamurthy P, Li D, Bou-Zeid E (2017b) High-resolution simulation of heatwave events in New York City. Theor Appl Climatol 128:89-102. https://doi.org/10.1007/s00704-015-1703-8

Rotach MW, Vogt R, Bernhofer C, Batchvarova E, Christen A, Clappier A, Feddersen B, Gryning S-E, Martucci G, Mayer H, Mitev V (2005) BUBBLE: an Urban boundary layer meteorology project. Theor Appl Climatol 81:231-261. https://doi.org/10.1007/s00704-004-0117-9

Salamanca F, Martilli A (2010) A new building energy model coupled with an urban canopy parameterization for urban climate simulations - part II. Validation with one dimension off-line simulations. Theor Appl Climatol 99:345-356. https://doi.org/10.1007/s00704-009-0143-8

Seidel DJ, Ao CO, Li K (2010) Estimating climatological planetary boundary layer heights from radiosonde observations: comparison of methods and uncertainty analysis. J Geophys Res Atmos 115:D16113. htt ps://doi.org/10.1029/2009JD013680

Stewart ID, Oke TR (2012) Local climate zones for urban temperature studies. Bull Am Meteorol Soc 93:1879-1900. https://doi.org/10.1175/BAMS-D-11-00019.1

Stull RB (1988) An Introduction to boundary layer meteorology. Kluwer, Dordrecht

United Nations, Department of Economic and Social Affairs, Population Division (2015) The world urbanization prospects: the 2014 revision. Department of Economic and Social Affairs, United Nations, p 493

Wallace JM, Hobbs PV (2006) Atmospheric science: an introductory survey. Elsevier, Amsterdam

Xu G, Xi B, Zhang W, Cui C, Dong X, Liu Y, Yan G (2015) Comparison of atmospheric profiles between microwave radiometer retrievals and radiosonde soundings. J Geophys Res Atmos 120:10313-10323. h ttps://doi.org/10.1002/2015jd023438 